\title{
El fenómeno de la subcontratación en Brasil y España. Principales diferencias y CUeSTiOnes Controvertidas de ambos Países
}

The phenomenon of outsourcing in Brazil and Spain. Main differences and controversial issues in both countries

\section{Pepa Burriel Rodríguez-Diosdado}

Profesora Lectora de la Universidad de Barcelona. Abogada.

E-mail pepaburriel@ub.edu

\section{RESUMEN}

El trabajo realizado en subcontratación constituye un régimen jurídico excepcional, altamente utilizado en la práctica brasileña y española. El problema reside en las peores condiciones de trabajo a las que pueden estar expuestos los trabajadores de las empresas de servicios, su mayor inestabilidad y la dificultad encontrar responsables, por ejemplo, en casos de conflictos en materia de salud laboral. Mientras que en España hay un importante desarrollo legal del fenómeno, logrando una equiparación de derechos y beneficios de los trabajadores de empresas prestadoras de servicios, en Brasil no existe un desarrollo legal, completo del tema por el momento, solucionándose los conflictos a través de la jurisprudencia consolidada del Tribunal Superior de Trabajo. El presente escrito tiene como finalidad poner de manifiesto las debilidades del sistema brasileño actual tomando como parámetro el desarrollo del sistema español.

Palabras Clave: Subcontratación. Precarización. Empresas de servicios.

\begin{abstract}
Thelabor in outsourcingisanexceptional legal regime, highlyused in Brazilian and Spanishpractice. Theproblemistheworstworkingconditions to whichworkersmay be exposed to servicecompanies, mostinstability and difficultyfindingresponsible, forexample, in cases of conflicts in occupationalhealth. While in Spainthereisanimportant legal development of thephenomenon, achievingequalrights and benefits of employees of servicecompanies in Brazilthereis no legal, full development of thesubjectforthemoment, solucionándose conflictsthroughestab-
\end{abstract}


lishedjurisprudence of the Superior LabourCourt. Thisletterisintended to highlighttheweaknesses of thecurrentBraziliansystemtaking as parameterthedevelopment of theSpanishsystem.

\section{Keywords: Outsourcing. InSeCurity. Service companies.}

SumARIO: Planteamiento. El origen y los problemas del fenómeno. 1. La regulación del fenómeno del trabajo en régimen de subcontratación: una asignatura pendiente de la OIT. 2. La evolución de la regulación de la subcontratación en ambos países. 3. El concepto de subcontratación en Brasil y España. Los elementos característicos. 4. El proyecto de ley brasileño 4330/94 bajo el prisma de la legislación española. Conclusiones. Bibliografía.

\section{Planteamiento. El origen y los Problemas del fenómeno}

Con las expresiones de contratas y subcontratas nos referimos a un fenómeno más de externalización o descentralización de los servicios de la empresa, outsourcing en terminología anglosajona, figuras en las que con carácter general una parte de la actividad económica es realizada por empresas auxiliares a través de sus propios trabajadores. De tal manera que una empresa, a la que denominamos principal, comitente o contratante, encarga a otra empresa, auxiliar, denominada contratista, subcontratista o de servicios, la realización de una obra o la prestación de un servicio con sus propios trabajadores, asumiendo la principal la obligación de pagar un precio cierto a esta auxiliar.

La mencionada descentralización productiva puede llevarse a cabo a través de diferentes títulos jurídicos: contrato de empresa, contrato de ejecución de obra, contrato de arrendamiento de servicios o incluso concesión administrativa para la gestión indirecta de servicios públicos. Sn embargo la importancia cuantitativa y los numerosos problemas que suscita la subcontratación-tercerización merecen un análisis diferenciado.

El incremento en el uso de estas formas de descentralización responde básicamente a la mejor eficiencia económica ique se consigue a través de ellas, son un instrumento adecuado para la adaptación a la realidad económica, esto es, para lograr la flexibilidad o flexibilización productiva, su mejor competitividad. Permite, en muchos casos, un mayor grado de especialización, de cualificación de los trabajadores y una más frecuente utilización de los medios técnicos que se emplean, lo que influye positivamente en la inversión en nueva tecnología. Pero veremos que en la afectación a las relaciones laborales los efectos no serán ni mucho menos tan beneficiosos como los efectos económicos descritos, de ahí el interés que presenta este fenómeno. 
La "tercerización" de los servicios y actividades industriales nace y evoluciona como una consecuencia del desarrollo de la lógica del funcionamiento del sistema capitalista, por una necesidad básica: mantenerse competitivo frente a sus rivales; por ello, surgen en todo el mundo nuevas empresas y nuevas formas de vincularse jurídicamente con el trabajador, sin perder de vista esa finalidad de mejora de la competitividad.

Los trabajadores inmersos en fenómenos de contratación y subcontratación están expuestos como cualquier trabajador a los riesgos típicos de la relación laboral, pero junto a éstos, por el hecho de estar inmerso en una estructura empresarial compleja de contrataciones y subcontrataciones se produce un efecto multiplicador cuantitativo y cualitativo de los riesgos para con su salud laboral ${ }^{300}$, a saber, al concurrir en un mismo espacio los trabajadores estará expuestos a un doble riesgo: los de su propia empresa y los de las restantes empresas intervinientes en el fenómeno productivo. Cuantas más empresas intervengan en el proceso productivo mayores serán los riesgos potenciales.

Pero la mayor vulnerabilidad de los trabajadores de las empresas auxiliares también deriva, entre otros, de los siguientes factores concretos:

- $\quad$ Desconocimiento del centro de trabajo, sí existe concurrencia física de diversas empresas con sus respectivos trabajadores en un mismo lugar de trabajo. Los trabajadores de contratistas y subcontratistas desarrollan su actividad en un centro de trabajo ajeno, desconocido en principio para ellos, de manera que la exigencia en el cumplimiento de los deberes de información y formación en materia preventiva debía ser mayor, situación que no es habitual en la práctica, llegando en ocasiones a un incumplimiento manifiesto en el nivel de formación otorgado ${ }^{301}$.

- $\quad$ La desvinculación en la relación laboral del empresario principal o contratista con los trabajadores de las restantes empresas, considerándolos como ajenos, a pesar de que en ocasiones la parte de la producción que se descentraliza es la que más riesgo comporta ${ }^{302}$. En otras palabras, nos referimos a la ausencia de una relación laboral con la empresa principal, que

${ }^{300}$ GARCIA NINET, J.I. Obligaciones y responsabilidades en materia de seguridad y salud en los supuestos de contratas y subcontratas. Consideraciones en torno al art. 24 (coordinación de actividades empresariales) de la LPRL. En: AAVV, Descentralización productiva y protección del trabajo en contratas, Valencia, 2000. P. 278.

${ }^{301}$ MOLTÓ GARCÍA, J.L. MOLTÓ GARCÍA, J.I. La prevención de riesgos laborales de los trabajadores de las empresas de trabajo temporal en las empresas usuarias. Ministerio de Trabajo y Asuntos Sociales. Edita Instituto Nacional de Seguridad e Higiene en el Trabajo. Madrid, 2009. P. 15.

${ }^{302}$ MIÑARRO YANINI, M. La prevención de riesgos laborales en la contratación temporal, empresas de trabajo temporal, y contratas y subcontratas. Ministerio de Trabajo y Asuntos Sociales. Edita Instituto Nacional de Seguridad e Higiene en el Trabajo. Madrid, 2002. P. 511. 
sin embargo es la que se beneficia del producto de su trabajo, que puede dar lugar a la desatención de los trabajadores externos por parte de la empresa principal, dando lugar a diversos niveles de seguridad en un mismo centro de trabajo.

- $\quad$ Disminución de las condiciones de trabajo y disminución del gasto en prevención. En relación con la dualidad en la protección del trabajador, afirmamos que dada la finalidad principal de la subcontratación (reducción de costes empresariales y obtención de mayor beneficio a través de la descentralización productiva) a medida que se reproduce la subcontratación las condiciones de trabajo y seguridad en las que los trabajadores de las empresas auxiliares realizan su tarea sean cada vez peores.

- $\quad$ Precariedad en las relaciones laborales, esto así porque el mecanismo contractual mayormente utilizado por las empresas contratistas y subcontratistas utilizan para la incorporación de sus trabajadores es la contratación temporal, dado que la finalidad de la actividad es limitada en el tiempo. Los riesgos que se derivan de las modalidades temporales de contratación se sumarán a los propios de las contratas y subcontratas.

En definitiva, factores de la relación laboral tales como la reducción de la seguridad, la estabilidad, la igualdad y la debilidad sindical que inciden significativamente en un nivel menor de protección de la seguridad y salud de los trabajadores afectados por procesos de descentralización productiva como éste ${ }^{303}$, lo cual se refleja en el mayor número de accidentes de trabajo.

Esta modalidad de contratación -nacida en el boom del modelo neoliberal, en la década de los 90- fue vendida como la panacea para la recomposición salarial y para tener la posibilidad de elegir la empresa que más convenía a "los intereses de los trabajadores". Pero, en realidad, la subcontratación y otras nuevas formas de relación entre nuevas empresas y trabajadores han logrado imponer, tanto en la Unión Europea como más allá, un modelo de la desigualdad, de fraude laboral.

\section{LA REGULACIÓN DEL FENÓMENO DEL TRABAJO EN RÉGIMEN DE SUBCONTRATA- CIÓN: UNA ASIGNATURA PENDIENTE DE LA OIT}

Destacamos la carencia de una norma internacional de la OIT en esta materia, pues, como se profundizará más adelante en este apartado, tras diversas discusiones de la Conferencia Internacional del Trabajo a finales de la década de los 90 fue imposible lograr un acuerdo en diversos frentes tanto para la aprobación de una Recomendación como de un Convenio. Pero eso no significa que la OIT no haya dictado normas o recomendaciones que pudieran ser aplicables a fenómenos de

${ }^{303}$ CRUZ VILLALÓN, J. Outsourcing. Contratas y subcontratas. En: ponencia temática del X Congreso de Derecho del Trabajo y la Seguridad Social. Zaragoza, 1999. P. 33. 
subcontratación o tercerización y a la protección de los trabajadores en este ámbito. Vayamos por orden cronológico.

En primer lugar, apareció el Convenio $\mathrm{n}^{\mathrm{o}} 155$ de la OIT de 22 de junio de $1981^{304}$ sobre seguridad y salud de los trabajadores y medio ambiente de trabajo, ubicado dentro del objetivo principal de la OIT de búsqueda del bienestar integral del trabajador, en todos sus ámbitos. Se reconoce en este Convenio la incidencia en la seguridad y salud de los trabajadores implicados en una de estas formas de organización de la actividad empresarial, constituyendo un importante riesgo a proteger para el cumplimiento del objetivo principal mencionado.

Así, el art. 17 establecía como medida preventiva, que "siempre que dos o más empresas desarrollen simultáneamente actividades en un mismo lugar de trabajo, tendrán el deber de colaborar en la aplicación de las medidas previstas en el presente convenio".

Se trata de un planteamiento muy amplio de la concurrencia empresarial física, con independencia de la relación que pueda existir entre ellas, abarcando todos los supuestos en los que se dé la simultánea presencia en un mismo medio de trabajadores de una pluralidad de empresas. No se refería expresamente a la contratación y subcontratación pero, dada la extensión del precepto, estos fenómenos quedarían incluidos.

Asimismo, es un planteamiento poco concreto, ya que no se especifica esa obligación empresarial de colaboración, sino simplemente se establece como un deber esencial, básico, de garantizar la protección de los trabajadores en los supuestos de concurrencia locacional, debiendo encargarse de su desarrollo las legislaciones nacionales.

En este mismo Convenio se ofrece la definición de "lugar de trabajo" a los efectos de comprensión del texto, así el art. 3.c) en conexión con su propio apartado d) afirmaba que lugar de trabajo son "todos los sitios donde los trabajadores deben permanecer o adonde tienen que acudir por razón de su trabajo y que se hallan bajo el control directo o indirecto del empleador", alcanzando cualquier lugar en el que, por razón de trabajo, se solicite la presencia del trabajador, independientemente del tiempo de permanencia en el mismo pero, eso sí, siempre que el empresario pueda controlar el desarrollo de su actividad directa o indirectamente.

Algún autor ha destacado que en el Convenio no se especifica lo que debe entenderse por control inmediato o mediato del empresario sobre estos lugares dónde el trabajador es desplazado, generando un problema en orden a los límites de la responsabilidad empresarial y, por tanto de las obligaciones del empresario ${ }^{305}$.

En segundo lugar, la Recomendación $\mathrm{n}^{\mathrm{o}} 164$ sobre seguridad y salud de los trabajadores complementa el Convenio $\mathrm{n}^{\circ} 155$, estableciendo una regulación más detallada en cuanto al deber de colaboración empresarial.

${ }^{304}$ Ratificado por Brasil el 19 de mayo de 1992 y por España el 11 de septiembre de 1985.

${ }^{305}$ MiñarroYanini, M. Op. cit, p. 522. 
En primer término, el art. 11, especifica el art. 17 del Convenio en los siguientes términos: "cuando dos o más empresas desarrollen simultáneamente actividades en un mismo lugar de trabajo, deberían colaborar en la aplicación de las medidas relativas a la seguridad y salud de los trabajadores y el medio ambiente de trabajo, sin perjuicio de la responsabilidad de cada empresa por la salud y la seguridad de sus propios trabajadores. En casos apropiados, la autoridad o autoridades competentes deberian prescribir las modalidades generales de tal colaboración".

Este artículo sigue siendo un precepto demasiado amplio al tomar en consideración, al igual que el Convenio, la pluralidad de empresas en un mismo lugar de trabajo como factor determinación del deber de colaboración, sin atender al tipo de vínculo entre ellas, lo que vuelve a dar lugar a las inclusión de las contratas y subcontratas en el reconocimiento de dicha obligación.

Sin embargo, debemos destacar que con carácter diferenciador respecto al Convenio se añade que la colaboración que debiera existir no debe afectar a la responsabilidad, de hecho se mantiene que, en materia de prevención de riesgos laborales, recae sobre cada una de las empresas respecto de sus propios trabajadores.

$\mathrm{Y}$, asimismo, la referencia a la intervención de las autoridades competentes tampoco aparecía en el Convenio, aunque dada la amplitud de este art. 11 no se especifica cuando debe proceder esta actuación, esto es, cuando es apropiado o no la intervención y en qué consistirán las "modalidades generales" de tal colaboración prescritas por la autoridad.

En segundo término, el art. 16 de la Recomendación se ocupa de este deber de colaboración interempresarial en casos de concurrencia física, y establece reglas generales para su cumplimiento. Reza así: "el objetivo de las disposiciones adoptadas en virtud del artículo 17 del Convenio debería ser garantizar que los trabajadores:

a) Velen, dentro de límites razonables, por su propia seguridad y por la de otras personas

a quienes puedan afectar sus actos $u$ omisiones en el trabajo;

b) Cumplan las instrucciones dadas para garantizar su propia seguridad y salud, así

como las de otras personas, y observen los procedimientos de seguridad e higiene;

c) Utilicen correctamente los dispositivos de seguridad y el equipo de protección y no los hagan inoperantes;

d) Informen inmediatamente a su superior jerárquico directo de cualquier situación que, a su juicio, pueda entrañar un riesgo que ellos mismos no puedan remediar;

e) Informen acerca de todo accidente o daño para la salud que sobrevenga durante el trabajo o en relación a éste". 
Una de los cambios significativos con respecto al Convenio es que las medidas establecidas en el anterior artículo de la Recomendación van dirigidas a los propios trabajadores, alusión que hasta el momento no había aparecido en la normativa de la OIT. Pese al todavía carácter genérico del deber u obligación de colaboración interempresarial, con este último precepto se dibujan ya los perfiles del mismo, dando pautas relativas a la información y formación global, que deben conocer todos los trabajadores que coinciden en el mismo lugar de trabajo, de lo que se deduce el conocimiento de los riesgos del mismo y de las medidas de protección aplicables.

Pero al margen de estas dos disposiciones no ha sido posible el tratamiento unitario del fenómeno de la subcontratación por la OIT. La primera discusión sobre el asunto del trabajo en régimen de subcontratación tuvo lugar en la 85. ${ }^{a}$ reunión (1997) de la Conferencia Internacional del Trabajo. A raíz de dicha discusión, y de conformidad con el artículo 39 del Reglamento de la Conferencia, la Oficina Internacional del Trabajo preparó y envió a los gobiernos de los Estados Miembros un informe en el que figuraban un proyecto de convenio y un proyecto de recomendación sobre el trabajo en régimen de subcontratación, basados en las conclusiones que la Conferencia adoptó en su 85. ${ }^{a}$ reunión.

En realidad, el proyecto de Convenio contemplaba tres formas de trabajo en régimen de subcontratación: 1) una relación bilateral directa entre una empresa usuaria y un trabajador, sin que existiera un contrato de trabajo; 2) una relación trilateral entre una empresa usuaria y un trabajador puesto a disposición por un subcontratista no especificándose si éste es el empleador o si hay un contrato de trabajo entre ellos; y 3) una relación trilateral en la que el subcontratista es sustituido por un intermediario con el que el trabajador no está vinculado por un contrato de trabajo. En los tres casos, el trabajador presta sus servicios en condiciones de dependencia o subordinación efectivas respecto a la empresa usuaria.

Se invitó a los gobiernos a que enviaran las enmiendas u observaciones que desearan formular o a que comunicaran a la Oficina, si consideraban que los textos propuestos constituían una base apropiada de discusión para la 86. ${ }^{a}$ reunión (1998), con fecha límite el 30 de noviembre de 1997. E igualmente, de conformidad con el párrafo 6 del artículo 39 del Reglamento de la Conferencia, se pidió a los gobiernos que, antes de dar forma definitiva a sus respuestas, consultaran a las organizaciones más representativas de empleadores y de trabajadores y que indicasen cuáles eran las organizaciones consultadas.

El Gobierno de Brasil emitió respuesta, elaborada en consulta con las organizaciones de empleadores y trabajadores, tal y como había sugerido la OIT $^{306}$.

${ }^{306}$ Los gobiernos de los 16 Estados Miembros que se citan a continuación señalaron que sus respuestas habían sido elaboradas en consulta con las organizaciones de empleadores y de trabajadores: Brasil, Canadá, República Checa, Chipre, Dinamarca, Finlandia, Hungría, Kenya, Mauricio, Noruega, Seychelles, Singapur, Suecia, Suiza, Trinidad y Tabago y Zambia. 
A nivel general, se destacaba la conveniencia de adoptar una recomendación que regulara el trabajo en régimen de subcontratación en lugar de un convenio, dada la complejidad del tema, que incluía situaciones muy divergentes y diferencias desde el punto de vista técnico y jurídico entre los diversos Estados Miembros. Consideraba el Estado brasileño que una recomendación aportaría mayor claridad y proporcionaría directrices generales respecto de las diversas repercusiones que entraña el trabajo en régimen de subcontratación, señalándose que el texto propuesto, una vez enmendado -por ejemplo en cuanto a la controvertida definición del trabajo en régimen de subcontratación-, constituiría una base válida para su discusión en la próxima reunión de la Conferencia. En general, las definiciones propuestas, concluía el Gobierno, eran sustancialmente ambiguas y traducían la dificultad de establecer inequívocamente una definición del concepto de acuerdo de trabajo contractual, que revistiera formas diferentes de un Estado Miembro a otro.

Por su parte, laConfederación Nacional de la Industria en Brasil (CNI), de una manera más rotunda manifestaba que la adopción de un convenio para regular la subcontratación a nivel internacional era totalmente improcedente al imponer rigideces a los mercados de trabajo, poner en peligro los niveles de empleo y, por consiguiente, consecuencias socioeconómicas negativas, en especial en los países en desarrollo. Para esta asociación empresarial, dada la complejidad y diversidad del trabajo en régimen de subcontratación, sólo sería posible adoptar conclusiones y directrices generales, concluyendo que el texto de Convenio propuesto invadía el ámbito de las relaciones comerciales legítimas, que no entraban dentro del mandato de la OIT.

La Confederación Nacional del Comercio de Brasil (CNC), indicaba que los instrumentos que tenían por objetivo regular las condiciones de trabajo en situaciones específicas como esta no deberían revestir la forma de normas internacionales, reiterando la inflexibilidad y falta de realidad de la propuesta, que en sí representaría en su opinión un obstáculo para el recurso al trabajo en régimen de subcontratación.

En último lugar, la Central Única de Trabajadores (CUT) consideraba que el sistema de trabajo en subcontratación debería ser aceptado en calidad de régimen jurídico de excepción, y su práctica debería aceptarse únicamente a personas jurídicas. Según este sindicato no era aceptable incluir en la definición de «empresa usuaria» e «intermediario» a las personas físicas, insistiendo en que las normas del trabajo deberían favorecer el establecimiento de relaciones directas entre el trabajador y la empresa usuaria y permitir, sólo en forma excepcional, la actuación de intermediarios o de agentes jurídicos secundarios.

El Gobierno de España, por su parte, comenzaba sus consideraciones sobre el proyecto de convenio remitiéndose a la normativa interna, en la que el contratista responde de la realización de una obra o de la prestación de un servicio; el objeto del contrato es el resultado del trabajo, por lo que en él no se hace referencia a los trabajadores a título individual. Destacando que la definición del texto propuesto por 
la OIT, en lugar de centrarse en la dependencia y la subordinación, debería definir el trabajo en régimen de subcontratación como aquel que se realiza con intervención de uno o varios de los elementos que caracterizan la relación laboral; esto así, porque según el Estado español el problema radicaba en que el proyecto de convenio y el proyecto de recomendación crean de hecho una tercera categoría de trabajadores, independientemente de que figuren o no las palabras «análogas a las». En relación con otro problema terminológico que se planteaba se inclinaba por referirse sea en forma directa, sea en forma indirecta a los contratos de empleo únicamente utilizándose el término «contrato de trabajo». Sin perjuicio de las observaciones sobre algunas disposiciones específicas, la orientación general de los proyectos de instrumentos sobre trabajo en régimen de subcontratación no planteaba problemas internos para el sistema español de trabajo y seguridad social dado que, en España, a los trabajadores en régimen de subcontratación no sólo se les trata conforme a su situación particular, sino que también disfrutan de un nivel de protección similar al de los demás trabajadores.

La Oficina Internacional del Trabajo resumía su punto de vista, tras la recepción de todos los documentos, indicando que mientras que las organizaciones de empleadores consideran que en la primera discusión no se habían producido resultados satisfactorios, y que no era posible lograr instrumentos aceptables, las organizaciones de trabajadores mantenían la importancia de que se adoptara un convenio completado por una recomendación; es decir fuerte tendencia ideológica en las conclusiones de ambos interlocutores sociales. Y, por su parte, varios gobiernos habían indicado en sus observaciones generales que los textos adoptados en 1997 constituían una base adecuada para la discusión en 1998. Si bien es cierto, ponía de manifiesto cómo de los diversos trabajos y discusiones en el seno de las reuniones en el seno de la OIT se había revelado que los mandantes de la OIT, a través de sus Estados miembros, interpretaban y entendían de diferente manera varias e importantes cuestiones de naturaleza sustantiva tales como la definición del «trabajo en régimen de subcontratación», el alcance de los instrumentos propuestos y la terminología que había de utilizarse; por ello abogaba por seguir trabajando y armonizar los diversos conceptos y resolver las controversias relativas a la definición del trabajo en régimen de subcontratación.

No hubo después de este serio intento de convenio, salvo error u omisión por mi parte, una propuesta sincera de reglamentar la subcontratación del trabajo. Quizás las fuertes críticas de distintos países intervinientes hicieron desistir al organismo internacional.

\section{LA EVOLUCIÓN DE LA REgULACIÓN DE LA SUBCONTRATACIÓN EN AMBOS PAÍSES}

La carencia de una regulación normativa detallada, exhaustiva y sin ambigüedades ha generado en la realidad del trabajo en Brasil durante los siglos XX y 
XXI situaciones conflictivas que detallaremos más adelante. En España, la situación también ha sido definida a través de diferentes golpes de efecto que desarrollaremos en el mismo hilo cronológico.

Para entender el panorama actual debemos recurrir a cuáles son los parámetros legales y jurisprudenciales existentes en la actualidad en Brasil para la configuración de la figura de la subcontratación o tercerización, así como en un epígrafe posterior, el análisis del Proyecto de Ley que se encuentra encima de la mesa desde el año 2004 y que cambiaría el panorama actual, PL 4330/2004, no exento de polémica.

En primer lugar, el arte. 4 de la Ley de Introducción al Código Civil ${ }^{307}$ establece que cuando la ley no diga nada, el juez decidirá el litigio de conformidad con la analogía, las costumbres y los principios generales del derecho. Dada la falta de una legislación de tutela del tema en cuestión, es necesario buscar la solución en la interpretación sistemática del ordenamiento jurídico, en particular en los principios contenidos en la Constitución y en la Compilación de las Leyes de Trabajo brasileñas (en adelante, CLT).

Los principios son considerados como el marco legal, cuyo objetivo es facilitar la aplicación de las normas en casos concretos. Ellos tienen una gran relevancia en el sistema jurídico de Brasil, ya que son considerados como una guía y, en este sentido, no difiere en exceso del sistema jurídico español. El artículo 8 del CLT establece una función de los principios esenciales ante un vacío legal, disponiendo que las autoridades administrativas y los Tribunales de Trabajo, en ausencia de disposiciones legales o contractuales decidirán en base a la analogía, la equidad y otros principios y normas del derecho, sobre todo de derecho de acuerdo con los usos y derecho comparado, pero siempre sin ningún interés de clase en particular o prevalencia del interés público. Se establece asimismo, el derecho consuetudinario como fuente subsidiaria del derecho del trabajo, en el mismo sentido que el art. 3.1. d) del Real Decreto Legislativo 1/1995, de 24 de marzo, por el que se aprueba el Texto refundido de la Ley del Estatuto de los Trabajadores español (en adelante, ET).

Los principios propiamente laborales, y fundamentales, en ambos sistemas de derecho son los denominados principios protectores, esto es, pro operario, norma más favorable y condición más beneficiosa, los tres con el objeto de equilibrar las relaciones entre capital y trabajo, que por origen son desiguales. Con respecto al último de los principios enunciados, el de condición más favorable destacamos el art. 10 CLT que especifica que: "cualquier cambio en la estructura legal de la empresa no afectará a los derechos adquiridos por los trabajadores"; y, este mismo razonamiento, se reitera en el 468 del mismo CLT que dispone que en los contratos individuales de trabajo, sólo se permite cambiar las condiciones inicialmente pactadas de mutuo acuerdo, siempre y cuando no se produzcan, directa o indirectamente, daño al empleado, bajo pena de nulidad de la variación adoptada.

${ }^{307}$ Ley n$^{\mathrm{o}} 10.406$, de 10 enero 2002. 
Pero también es necesario destacar, en el sistema brasileño, el principio de la primacía de la realidad que prevé, en el caso de discordancia entre la realidad y los documentos de hecho o de los contratos existentes, la prevalencia de la realidad sobre la forma, con base en la verdad real, porque la realidad de los hechos no es objeto de ninguna manipulación por la voluntad humana y los documentos no pueden expresar con precisión la voluntad de las partes. Y, este principio ha sido inspirador en la solución de conflictos en la subcontratación.

La externalización de las estructuras empresariales en Brasil no se hace patente hasta los años 70, por eso cuando se redacta el CLT en 1943, el fenómeno no mereció una atención especial.

Las primeras normas en torno a la subcontratación se producen en el ámbito público, eso es lo que sucedió con el Decreto-Ley n ${ }^{\circ}$ 200/67 (art. 10) y la Ley $\mathrm{n}^{0} 5.645 / 70^{308}$, especifica qué servicios públicos podrían ser subcontratados, refiriéndose a las actividades relacionadas con el transporte, conservación, custodia, funcionamiento de ascensores, limpieza y otros similares.

Estas normas respondieron a un cambio en el escenario público, puesto que el propio Estado había adoptado la subcontratación como parte de la descentralización administrativa y fueron seguidas de otras, así se crearon reglas específicas adicionales para la contratación externa, en el marco de empresas de trabajo temporales (Ley 6.019/74) y en los servicios de monitoreo de banco (Ley 7.102/83).

El 9 de diciembre 1985 se publicó la Doctrina del Tribunal Superior de Trabajo ${ }^{\circ} 239$ quién declaraba la ilegalidad de la cesión de trabajadores en el sector bancario, concretamente referida al traspaso de trabajadores entre empresas pertenecientes al mismo grupo de empresas bancario. La recopilación o Suma fue editada porque era necesario frenar el fraude que se estaba produciendo en el sector ${ }^{309}$.

$\mathrm{Y}$ en este contexto de desorden y la inseguridad jurídica causada por las distintas normas, el Tribunal Superior del Trabajo vuelve a editar la doctrina consolidada a través de la Suma ${ }^{\circ} 256$ en 1986, para guiar las decisiones sobre el asunto, destacándose que, salvo en los casos de trabajo temporal y el servicio de vigilancia previstos en las Leyes $\mathrm{n}^{\circ} 6019$ y n $^{\circ} 7102$, era ilegal contratar a trabajadores a través de una empresa intermediaria, que realizan el trabajo directamente con el prestatario de los servicios.

La Ley $n^{0} 8.863 / 94$ prorrogó la hipótesis de la externalización para los sectores de la vigilancia pública o privada, no sólo referido a empresas sino también a personas físicas.

De tal manera, que con la legislación brasileña en la mano en el ámbito privado, sólo estos dos tipos de externalización -a través de empresas de trabajo tem-

${ }^{308}$ DELGADO, M. Curso de Derecho del trabajo del curso. Sao Paulo: LTr, 2002. p. 418419.

${ }^{309}$ En este sentido, MARTINS Sergio Pinto. La subcontratación y la legislación laboral . $3^{\text {a }}$ ed. Sao Paulo:Malheiros, 1997. p. 14. 
poral y el sector de la vigilancia o seguridad, se encontraban permitidos por la ley.

En España, Ley 8/1980, de 10 de marzo, del Estatuto de los Trabajadores mantenía casi la misma configuración que el actual ET de 1995 permitiendo la subcontratación en su art. 42, ya derogado, entre empresas, para todo tipo de sectores y relativa a la denominada actividad inherente de la empresa contratante. Sin embargo, en el art. 43 ET prohibía e ilegalizaba toda cesión de trabajadores o intermediación laboral que no fuera pública, esto es a través de los servicios de empleo públicos. Las Empresas de Trabajo Temporal (ETT) se encontraban prohibidas en nuestra legislación laboral hasta 1993, pero con la Ley 14/1994 de 1 de junio obtienen una regulación completa y se autoriza la intermediación laboral -la cesión de mano de obra- a través de ellas; es importante tener en cuenta que esta norma, todavía vigente, establece unos estrictos requisitos para la constitución de $\mathrm{ETTs}^{310}$, y la responsabilidad de ésta en materia de salario y seguridad social de los trabajadores a su cargo y formativas -la ETT está obligada a destinar anualmente al menos un $1 \%$ de la masa salarial de los trabajadores contratados para ser cedidos y, por tanto, a ella le corresponde formar al trabajado-. La empresa contratante, denominada en este caso, empresa usuaria, tendrá una responsabilidad subsidiaria en materia de salario y seguridad social, y sólo solidaria si se han incumplido los límites de la cesión.

En Brasil, la ley 8.949/94, de 9 diciembre de 1994 introdujo el párrafo único del art. 442 CLT, fomentando la externalización a través de cooperativas, al afirmar que independientemente de la rama de actividad de la sociedad cooperativa, no existe una relación laboral entre ella y sus miembros, o entre éstos y los tomadores de ese servicio.

Esta modificación legal abrió posibilidades de fraude, al permitir la cesión de mano de obra sin el marco legal de la empresa temporal constituida para ello, reflejándose en el aumento de las demandas laborales, con pronunciamientos judiciales contradictorios, generando una singular inseguridad jurídica.

La doctrina consolidada del Tribunal Superior de Trabajo brasileño de 1994, a través de la Suma n 331 trató de aclarar el contrapunto entre ofertas lícitas e ilícitas y de externalización con cuatro casos, excepcionales, en los que era posible y legal la externalización, así, el trabajo temporal para cubrir necesidades transitorias - para reemplazo de trabajadores regulares y permanentes de la empresa o para una necesidad extraordinaria y secundaria de la empresa-, vigilancia, servicios de mantenimiento y limpieza, y servicios especializados relacionados con las actividades accesorias o secundarias del servicio del prestatario.

\footnotetext{
${ }^{310}$ En la actualidad, deben cumplir los siguientes requisitos: una autorización administrativa para su constitución; la dedicación exclusiva de la empresa a tal actividad; la carencia de obligaciones pendientes de carácter fiscal o de Seguridad social por parte de la empresa (o sociedad o socios); el establecimiento de una garantía financiera a disposición de la autoridad laboral a la que corresponda conceder la autorización administrativa (para asegurarse el cumplimiento de las obligaciones salariales y de seguridad social de la futura ETT).
} 
La empresa que realiza servicios especializados, a saber, la vigilancia, mantenimiento y limpieza y relacionados con la actividad a través de debe realmente se especializa en ese tipo de servicio, y debe tener una formación específica. Esto significa que no puede ser una simple contratación de mano de obra calificada, debe ser especializado.

La ausencia de subordinación jurídica (directa) con el servicio asegurado era una de las condiciones para la legalidad de la contratación externa. Los trabajadores tercerizados debían mantener esos vínculos con el proveedor de servicios, y no con el prestatario. Si se queda caracterizada la subordinación legal se establecía la relación de trabajo y con ello el cumplimiento de todas las normas laborales.

Según Paulo Moraes la Suma 331 incidía en la necesidad de que los servicios $-\mathrm{y}$ los trabajadores- fueran especializados precisamente para evitar el simple suministro de mano de obra calificada, afirmando que de ello se deduce que el prestador de servicios debe ser una empresa que se especializa en ese tipo de servicio, que tenga una capacitación y organización para llevar a cabo el servicio que se le propone y que ese es precisamente el objeto de la concesión ${ }^{311}$.

La legalización de la externalización en los servicios de telefonía vino en Brasil de la mano de la Ley 9.472/97, de 16 julio 1997 y en las empresas de prestación de servicios públicos, en la forma definida en la Ley 8.987/95.

El Ministerio de Trabajo y Empleo brasileño, teniendo en cuenta la necesidad de estandarizar el procedimiento de control del trabajo en el ámbito de la tercerización, máxime después de la Sentencia $n^{0} 331$, emitió la Instrucción normativa $\mathrm{n}^{\mathrm{o}} 3$ agosto de 1997, que prevé la supervisión del trabajo en las empresas con el fin de prevenir el fraude en la contratación externa. En dicha instrucción se hacía hincapié en que para la prestación de servicios a terceros era necesaria la válida constitución de la empresa y la especialización de la misma, pues la finalidad de la externalización era lograr una especialización y eficiencia en ese servicio, que no se correspondía con la actividad básica de la empresa que externaliza pero sí era actividad habitual de la empresa de servicios.

Se determinó además que el prestatario y el contratista debían desarrollar diferentes actividades y tener diferentes efectos en el mercado, así como diferenciar a sus empleados quienes debían depender técnica y disciplinariamente de la empresa para la que fueron contratados.

Dada la inseguridad jurídica creada por la carencia de una norma omnicomprensiva del fenómeno de la subcontratación tanto en el ámbito público como en el privado se sucedieron los proyectos de Ley, con objeto de modificar la Ley 8.666/93, para regular la subcontratación de servicios en el sector público, tales

\footnotetext{
${ }^{311}$ Moraes, Paulo Almeida de Douglas. Contratación indirecta y servicios de outsourcing en la actividad principal de las personas jurídicas: la capacidad jurídica y la conveniencia social. . 2003 Disponible en:<www.mte.gov.br / policía / ms / ms_monografia.pdf > . Consultado el 16 de julio de 2014. P. 101.
} 
como los proyectos 1.292/1995, 1.587/2003, 6.420/2005 y 6.894/2006.

En el caso del sector privado, se destaca el diseño del Proyecto de Ley $5.439 / 2005$, que prohíbe el uso de mano de obra interpuesta. Este proyecto fue presentado por la Sra. Ann Bridges, con la intención de añadir al Código de Trabajo brasileño un nuevo art. 442, que manifestara que "Salvo en los casos de trabajo temporal -a través de empresas de trabajo temporal-, la vigilancia, los servicios de mantenimiento y la limpieza, se prohibe la contratación de trabajadores a través de una empresa intermediaria", añadiéndose además que en las obligaciones laborales y de seguridad social para con el trabajador regiría la responsabilidad solidaria entre la empresa prestataria y la prestadora, siempre que haya sido así declarado por un procedimiento judicial de ejecución.

Según la propuesta, la prohibición podría contribuir eficazmente a reducir la precariedad laboral y el fraude ahora regulada únicamente por la Sentencia nº331 del Tribunal Superior del Trabajo.

Sin embargo, en junio de 2005, el proyecto se adjuntó a un Proyecto previo, el PL 4.330/2004, cuyo autor es el Sr. Sandro Mabel, que establece a, grandes rasgos, la ausencia total de relación laboral entre el contratista y los empleados del contratista y la aplicación de las normas de derecho civil para determinación de las relaciones entre las sociedades. Su contenido y las polémicas en torno a él serán analizados en otro epígrafe.

\section{El concepto de subcontratación en Brasil y España. Los elementos CARACTERÍSTICOS}

La contratación y subcontratación de obras o servicios son expresión de la libertad de empresa que reconoce la Constitución Española en su artículo 38 y la Constitución brasileña en su art. 170 .

La subcontratación en Brasil, denominada tercerización, no encuentra desarrollo legal completo y exhaustivo, pero sí se sienta el siguiente principio básico: la contratación de trabajadores a través de una empresa intermediaria es ilegal, dando lugar a un vínculo jurídico laboral entre el trabajador y el receptor o beneficiario de los servicios, esto es la empresa principal; esta regla general admite excepción, esto es, que se trate de trabajo temporal, conforme todo ello a la Ley $\mathrm{n}^{\circ} 6019$, de 3 de enero de 1974 y los casos que, a continuación, veremos. En este postulado o fundamento jurídico, se está prohibiendo directamente la denominada "cesión ilegal de trabajadores" que se realice fuera de un trabajo típicamente temporal, en el mismo sentido que en España el art. 43 del ET prohíbe la cesión de trabajadores al margen del marco de las denominadas Empresas de Trabajo Temporal.

La Suma o Recopilatorio de la doctrina consolidada brasileña $\mathrm{n}^{\circ} 331$, del Tribunal Superior de Trabajo (TST) del 4 de enero de 1994, resume en los siguientes postulados la única forma de legalidad de esta descentralización productiva en el 
sector privado, a saber ${ }^{312}$ :

En primer lugar, debe existir una relación entre dos empresas, ambas con capacidad económica, pues es imprescindible que la empresa contratada -la no principal o empresas de servicios- se encuentre en condiciones de asumir los riesgos derivados del negocio jurídico - mercantil- incluyendo las obligaciones para con los trabajadores. Asimismo, la dirección de la actividad que se externaliza debe ser a cargo de la empresa no principal, la empresa de servicios, teniendo por tanto los trabajadores el vínculo jurídico laboral con ella y nunca al contario, con la empresa contratante.

En segundo lugar, una limitación en cuanto al tipo de prestación de servicios, esto es, que los servicios que son contratados por la empresa principal sean servicios especializados, tales como la vigilancia o seguridad (Ley $\mathrm{N}^{\circ} 7.102$, de 20.06.1983.), la higiene o limpieza, el mantenimiento, servicios de alimentación o restauración, y la asistencia técnica, entre otros. En este sentido, al tratarse de actividades especializadas el personal que los preste debe ser también especializado, ya que la utilización de personal no especializado es un claro indicio de ilicitud o ilegalidad de la tercerización. Tal y como hemos visto éste ha sido el resultado de la evolución normativa y jurisprudencial del país.

En tercer lugar, y en conexión con el anterior, con carácter general, los servicios que sean externalizados o descentralizados por parte de la empresa principal no deben consistir en la colaboración con la actividad principal de la empresa sino, al contrario, tratarse de las denominadas actividades-medio o actividades secundarias que no contribuyen al objeto social de la empresa principal. Detengámonos aquí, ya la elaboración de esta nota característica es fundamental para entender la conceptualización de la subcontratación en Brasil.

El problema más común en la caracterización de la licitud o ilicitud de la subcontratación es la distinción entre actividad-medio (legal) y actividad-final (ilegal).

La denominada actividad fin está conectada con la finalidad de la empresa, el objetivo de la producción empresarial o prestación de servicios. Es una actividad indispensable, sin la cual la propia empresa pierde su utilidad. Podemos recurrir al art. 581.§.2 de la CLT que nos trae una buena definición de la actividad fin: "(...) se entiende por la actividad principal que caracteriza a la unidad de producto, operación o meta final, cuyo logro para todas las demás actividades convergen exclusivamente bajo la conexión funcional'. Por tanto, la actividad fin viene generalmente descrita en el objeto del contrato social de la empresa; sin embargo, debido a la diversificación de los negocios y la relevancia del mercado es posible que el contrato social esté reñida con la actividad principal de hecho, por lo que algún autor

${ }^{312}$ Un resumen o esquematización de las notas características puede encontrarse en VARGAS, Luiz Alberto de; SILVEIRA, AlmirGoulart da. Terceirização e o enunciado 331 DO TST. Breves considerações. Disponible en: http://lavargas.sites.uol.com.br/terceira.html. 
ha considerado que si en el contrato social existen una multitud de objetos sociales, nos encontramos ante una clara evidencia de mera intermediación ilícita o tráfico de mano de obra calificada ${ }^{313}$. Y es ahí cuando para el análisis de la actividad fin, se debe utilizar el principio de la primacía de la realidad, impidiendo fraudes en el marco normativo de protección, de conformidad con el art. 9 de la CLT ${ }^{314}$.

En la práctica, por tanto, la verificación de la actividad principal de la empresa se realiza a través del análisis de su contrato social; de tal manera que si el trabajador lleva a cabo alguna actividad que contribuye a la producción de objetos sociales, no está proporcionando un servicio externalizado y puede derivarse una relación de trabajo directamente con el contratante y no con la empresa de servicios, según lo determinado por los Precedentes-Suma- no 331 del Tribunal Superior del Trabajo. Cuando se trata de la actividad principal, la subcontratación es ilegal.

Por su parte, la actividad-medio puede ser definida, por contraposición a la actividad fin como aquella que no coincide con los principales propósitos de la empresa, añadiéndole por ejemplo las notas de actividad secundaria, de apoyo o complementaria ${ }^{315}$.

El trabajo del fiscal, Maurice Correia de $\mathrm{Melo}^{316}$ explica que las actividades intermedias y finales pueden ser comparadas con el cuerpo humano. Algunas partes de nuestro cuerpo son más esenciales que otras. El cerebro, por ejemplo, es esencial, no se puede "subcontratar", pero una persona puede sobrevivir perfectamente sin un dedo o un pedazo de la mano. Para el fiscal, las empresas también tienen actividades que son esenciales, las que definen la empresa y otras actividades que son de apoyo, a continuación, que pueden ser externalizados.

La carencia de una definición legal ha generado cierta inseguridad jurídica, habiendo sido los Tribunales los encargados, en cada caso concreto de señalar sí la actividad era principal o no. Algunos pronunciamientos interesantes se han ofrecido, por ejemplo, en el sector bancario para deslindar ambos conceptos y declarar la cesión legal o ilegal ${ }^{317}$; téngase en cuenta que en caso de cesión ilegal se dará "la

${ }^{313}$ En este sentido, De Oliveirea Ramos, M. citada por Moraes, Paulo Almeida de Douglas. Contratación indirecta y servicios de outsourcing en la actividad principal de las personas jurídicas: la capacidad jurídica y la conveniencia social. 2003 Disponible en: www. mte.gov.br / policía / ms / ms_monografia.pdf. Consultado el 16 julio 2014. P. 100.

${ }^{314} \mathrm{El}$ art. 9 CLT establece que automáticamente se anularán los actos realizados con el fin de distorsionar, evitar o eludir la aplicación de los preceptos contenidos en esta consolidación.

${ }^{315}$ En un sentido similar, se expresa, MARTINS, Sergio Pinto. La Ley de Subcontratación y Trabajo. $9^{a}$ ed. rev. y ampl. Sao Paulo: Atlas 2009. P.128, dando ejemplos en el sector de la limpieza, la automoción o la banca.

${ }^{316}$ Correia de Melo, Maurice. Programa Entrevista Foro, Court TV, salió al aire el 22 de marzo 2010 Disponible en: http://www.youtube.com/watch?v=6eNf09c-Y9w. Consultado 19 julio 2014.

${ }^{317}$ Sobre la cesión ilegal por la externalización de la actividad principal y no de la activi- 
solidaridad entre las empresas demandadas, que se basa en la realización de un acto encaminado a obstaculizar y estafar la aplicación de los preceptos laborales (art. 9 CLT)" "318, y se impone el reconocimiento del contrato de trabajo directamente con el receptor de los servicios -la empresa contratante- ${ }^{319}$. Los Tribunales también se han encargado de manifestar que la tercerización de la mano de obra implica salarios significativamente más bajos para los trabajadores de las empresas de servicios que para los trabajadores de la empresa contratante o receptora de los servicios, señalándose que la "(...) externalización de la mano de obra tiene por objeto unas relaciones sociales flexibles si se utilizan para de manera legal, pero sin embargo, no puede servir como una forma de evadir las normas laborales, lo que agrava la desigualdad social de las categorías profesionales en aras de la contención de costos de mano de obra" $320 \mathrm{y}$, en definitiva, "la contratación de la mano de obra humana a través de una empresa intermediaria no es aceptado en nuestro sistema legal (salvo las disposiciones especiales de la Ley 6.019/74 y 7.102/83)"321.

En el sector de las telecomunicaciones, donde rige la Ley n ${ }^{\circ}$ 9472/97 también han sido frecuentes las discusiones en sede judicial sobre las denominadas "actividades inherentes" y su significado. El art. 94. §. II de la Ley, permite la contratación de empresas de servicios para el desarrollo de actividadesconexas, accesorias o complementarias al servicio". La dudaestablecida se refiere a la tendencia interpretativa que considera "actividadinherente " como actividadfin. La interpretación de la jurisprudencia laboral es que "las actividadesinherentes, accesorias o complementarias" se refiere a actividad-medio ${ }^{322}$.

En último lugar, la responsabilidad subsidiaria de la contratante en caso de incumplimiento de la empresa prestadora de servicios, de las obligaciones con

dad-medio en el sector bancario se alzan estos pronunciamientos: en el año 2002, ROAR -. 804604-93.2001.5.05.5555, Ministro Ponente: IvesGandraMartinsFilho, fecha de la sentencia: 20/08/2002, Subsección II Especializada en la negociación individual, Fecha de publicación: 27/09/2002; y en el 2009, TRT tercera Región -0068200-49.2009.5.03.0062 RO - RO Cuarto Panel -. Relator Des LuizOtávioLinhares Renault - 30/11/2009 p.

${ }^{318}$ TRT tercera Región - Séptima Clase - 02309-2006-136-03-00-0 RO - Relator convocó WilméiaBenevides da Costa - 12/04/2007 p.

${ }^{319}$ TRT $6{ }^{\text {a }}$ Región - Primera Clase - RO - 00.746 hasta 2.009 - 005-06-00-9 - Relator Bartolomé Alves Bezerra - 13/05/2010 $p$.

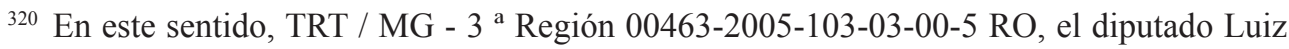
Felipe Vieira de Mello Filho, quinta clase, Publicado 09/07/2005.

${ }^{321}$ Así se expresa, la TRT / MG - $3{ }^{\text {a }}$ Región 00176-2004-088-03-00-6 RO, el representante Paul Costa Roberto Sifuentes, tercera clase, publicado 18/12/2004.

${ }^{322}$ En este sentido, resolvieron, en Proceso No TST-RR-66800-44.2009.5.03.0112. Tribunal Superior del Trabajo. Órgánojuzgador: $5^{\mathrm{a}}$ turma. Relatora: Ministra KátiaMagalhãesArruda. Publicado en DEJT el 14/10/2011; y el proceso No TST-RR-134200-39.2009.5.04.0018 Órgánojuzgador: $2^{\mathrm{a}}$ Turma, Relator: Min. Caputo Bastos. Publicado no DEJT em 16/09/2011. 
los trabajadores, siempre que hayan participado en la relación procesal y también se incluye en la aplicación judicial. Nos estamos refiriendo a que la subcontratación sea legal pero la empresa de servicios no pague los salarios a los trabajadores o no abone los conceptos de seguridad social correspondientes; en caso que la cesión fuera ilegal, la responsabilidad que se generaría para los dos implicados en la relación mercantil -contratante y prestador- sería subsidiaria.

En España se consideran formas lícitas en base al art. 42 ET mientras no contraríen el ordenamiento jurídico, encontrándose los perfiles con la cesión ilegal de mano de obra muy próximos a estas figuras ${ }^{323}$, teniendo en cuenta además que en nuestra legislación tampoco existe una definición del fenómeno de subcontratación. Por ello, la doctrina judicial española ha recurrido a la aplicación de diversos criterios de valoración que no son excluyentes, sino complementarios, y que tienen un valor indicativo u orientador, tales como: la justificación técnica de la contrata, la autonomía de su objeto, la aportación de medios de producción propios (Sentencia del Tribunal Supremo 7-03-1988), el ejercicio de los poderes empresariales por parte de la empresa que presta el servicio (Sentencias del Tribunal Supremo de 12-09-1988, 16-02-1989, 17-01-1991 y 19-01-1994) y la realidad empresarial del contratista, que se pone de manifiesto en relación con datos de carácter económico (capital, patrimonio, solvencia, estructura productiva).

En definitiva, la Sentencia del Tribunal Supremo de 30 de mayo de 2002, que es doctrina consolidada de la Sala de lo social, afirmaba que la línea divisoria entre los supuestos de subcontratación lícita y de pseudocontrata o cesión ilegal de trabajadores bajo falsa apariencia de contrata de obras o servicios ha de ser trazada de acuerdo con la doctrina del empresario efectivo ${ }^{324}$, debiendo ponderarse el desempeño de la posición empresarial no de manera general sino en relación al trabajador concreto que la solicita ${ }^{325}$.

De tal manera que las empresas contratistas que asuman la posición de empresarios o empleadores respecto de sus trabajadores, ejerciendo su poder de dirección y haciendo frente a las responsabilidades propias de su posición se considerarán subcontratación lícita, regulada por el art. 42 ET; por el contrario, los casos de contratas ficticias de obras o servicios que encubren una "mera provisión de mano de obra" constituirán cesión ilegal de trabajadores, prohibida y regulada por el 43 ET, en los siguientes términos en el apartado 2: “(...) se entiende que se incurre en la cesión ilegal de trabajadores contemplada en el presente artículo cuando se produzca alguna de las siguientes circunstancias: que el objeto de los contratos de servicios

${ }^{323}$ Sentencia del Tribunal Supremo 25-10-1999, Sentencia del Tribunal Superior de Justicia de Catalunya de 1-01-2001, Sentencias del Tribunal Supremo 14-03-2006 y 4-03-2008, entre otras.

${ }^{324}$ Sentencias del Tribunal Supremo de 11-07-1986, 1-07-1993, 11-10-1993, 18-03-1994 y 12-12-1997, entre otras.

${ }^{325}$ Sentencias del Tribunal Supremo 12-09-1988 y 19-01-1994. 
entre las empresas se limite a una mera puesta a disposición de los trabajadores de la empresa cedente a la empresa cesionaria, o que la empresa cedente carezca de una actividad o de una organización propia y estable, o no cuente con los medios necesarios para el desarrollo de su actividad, o no ejerza las funciones inherentes a su condición de empresario".

Asimismo, ha sido labor jurisprudencial la delimitación de los requisitos necesarios para la calificación de una empresa como empresa contratista -prestadora de servicios- ${ }^{326}$. Se pueden resumir en los siguientes:

- $\quad$ Disponer de una organización autónoma e independiente, incluyendo todos los medios materiales y personales necesarios (sede, plantilla y titularidad de los medios materiales utilizados).

- $\quad$ Asunción de la organización, el control y la dirección de la actividad, encontrándose los trabajadores sujetos a sus órdenes e instrucciones. - $\quad$ El objeto ha de ser una actividad específica y delimitada, por lo que se ha de poder diferenciar de la propia actividad de la empresa principal.

- $\quad$ Asunción de las responsabilidades y los riesgos de la actividad empresarial.

El último elemento a destacar del fenómeno de la subcontratación en España es la "propia actividad". El art. 42 ET lo incluye como nota caracterizadora de la subcontratación legal, de tal manera que las actividades descentralizadas por una empresa en el marco de este artículo sólo pueden referirse a su propia actividad, concepto interpretado desde el año 1995 y que ha sido objeto de múltiples pronunciamientos.

Los primeros pronunciamientos del Tribunal Supremo en torno a este concepto partían de un concepto estricto, considerando como tal la actividad inherente o absolutamente indispensable para el objeto de la empresa principal ${ }^{327}$; es decir "la propia actividad" de la empresa principal engloba aquellas operaciones o labores que corresponden a su ciclo productivo, en concreto las que son inherentes a la producción de bienes y servicios específicos que se propone prestar ${ }^{328}$ excluyendo las tareas complementarias o no nucleares. Por tanto, no sería propia actividad aquellos

326 Sentencias del Tribunal Supremo 25-10-1999, 21-03-1997, 18-03-1994, 17-02-1993, 17 marzo 1993, 11-10-1993, 15-11-1993.

${ }^{327}$ Entre otras muchas, vid. Sentencias del Tribunal Supremo 18-1-1995, 24-11-1998, 27-102000, 22-11-2002, 18-1-2010, 3-7-2012.

${ }^{328}$ Algunas de los casos planteados que afirman la existencia de "propia actividad" son: Sentencia del Tribunal Supremo 24-11-1998: un servicio de comedor y cafetería en un Colegio Mayor; Sentencia del Tribunal Supremo 3-7-2012: entre empresa de proyectos basados en el uso intensivo de la tecnologías de la información y constructora; Sentencia del Tribunal Supremo 15-4-2010: entre entidad bancaria y empresa de servicios informáticos. 
servicios y obras desconectados de la finalidad productiva y de las actividades normales de la empresa comitente y las actividades complementarias o auxiliares que no absolutamente esenciales ${ }^{329}$.

En definitiva, será el examen de cada supuesto concreto el que revele la existencia de dicha condición ${ }^{330}$.

Como efecto básico de la denominada cesión ilegal se deriva la responsabilidad solidaria de las empresas participantes, sin posibilidad de exclusión alguna. Sin embargo, en materia de subcontratación válida existe una pequeña variación en materia de responsabilidad: la empresa contratante durante el año siguiente a la terminación del servicio responderá de manera solidaria de las obligaciones de naturaleza salarial contraídas durante el encargo por las empresas de servicios o auxiliares intervinientes en la operación (art. 42.2 ET); sin embargo con respecto a las obligaciones en materia de seguridad social existen variaciones: primero, el empresario contratante o principal deberá comprobar que las empresas de servicios con las que se contrata están al corriente del pago de las cuotas de la seguridad social, librándose de responsabilidad solidaria de las deudas que se contraigan durante la vigencia del servicio, una vez expedida la certificación o transcurridos 30 días sin contestación de la Administración, pero manteniendo una responsabilidad subsidiaria de las cuotas a la seguridad social que el contratista tuviera pendientes de pago -no prescritos- a la hora de suscribir el contrato mercantil -arts. 104 y 127 de la Ley General de la Seguridad social-; segundo, la responsabilidad subsidiaria en materia de cuotas de la seguridad social aparecerá cuando la actividad que se haya externalizado no corresponda a la propia actividad.

Si tenemos que realizar una comparativa de elementos básicos nos encontraríamos con que tanto en Brasil como en España son dos empresas legalmente constituidas y con la suficiente solvencia las que pueden realizar servicios externalizados, tanto activa como pasivamente; asimismo, por el lado de los trabajadores, se destaca en ambos países que el vínculo laboral, si la institución es legal y válida, no se genera con la empresa principal sino con la empresa secundaria realizadora del servicios; pero, en tercer lugar se alza la diferencia fundamental pues si en España la descentralización a través de la subcontratación debe referirse a la actividad esencial

${ }^{329}$ A modo de ejemplo, la Sentencia del Tribunal Supremo 28-10-2010 considera que no es propia actividad la desarrollada entre empresa y contratas de labores de vigilancia de edificios, locales y centros de trabajo; y la Sentencia del Tribunal Superior de Justicia de Cataluña 4-4-2003 afirma que tampoco hay propia actividad entre Renfe y la empresa dedicada a la venta de billetes, información al pasajero, limpieza y mantenimiento. En el mismo sentido negativo se expresa la Sentencia del Tribunal Superior de Justicia de Madrid 30-5-2011 que niega la propia actividad entre la actividad de una aerolínea y la empresa que realiza la limpieza de los aviones.

${ }^{330}$ Sentencias del Tribunal Supremo 20 junio de 2005, 22 noviembre de 2002, 27 marzo de 2001, 10 julio de 2000, entre otras. 
de la empresa -concepto de gran desarrollo jurisprudencial como a continuación veremos-, en Brasil sólo sería válida aquella descentralización referida a actividad no principales, actividades medio de las cuales además constan diversos ejemplos -vigilancia, limpieza, mantenimiento, servicios de restauración o asistencia técnica-.

\section{El PROYECTO dE LEY BRASILEÑO 4330/94 BAJO EL PRISMA DE LA LEGISLACIÓN ESPAÑOLA}

El giro radical en la propuesta de ley de subcontratación ha provocado no pocas manifestaciones en su contra, a continuación desarrollamos las últimas, más significativas.

En primer lugar, las movilizaciones sociales de parte de los sindicatos, destacando las diversas acciones del sindicato IndustriaALL en julio de $2013^{331}$, básicamente por tres motivos: a) porque el proyecto de Ley aboga por un mercado laboral más flexible; b) porque debilitaría la relación laboral; c) porque mermaría la fuerza de acción de los sindicatos. Y, en este último aspecto, se destaca que, a pesar de la falta de regulación de la subcontratación y de las dificultades que tienen los sindicatos sectoriales para organizar a los trabajadores precarios, el sindicato mencionado ha logrado algunos acuerdos para limitar el uso de trabajadores subcontratados a nivel de la empresa; por ejemplo, el sindicato de trabajadores de la química en la región de Rio de Janeiro negoció la firma de un código de conducta con la empresa Bayer para limitar el uso de trabajadores precarios, de tal manera que la empresa no puede recurrir a subcontratistas sin consultar al sindicato; también el sindicato de trabajadores metalúrgicos ha conseguido un acuerdo similar con la empresa Mercedes-Benz en la región de Sao Paulo, la dirección y el comité de empresa negocian la tasa de trabajadores subcontratados que se emplearán en las plantas.

En segundo lugar, los presidentes de las Universidades y de los Fiscales de los Tribunales Regionales del Trabajo fueron llamados a dar su opinión en una audiencia pública sobre el Proyecto de Ley, y de este análisis preliminar se publicó una carta abierta firmada por los miembros de Coleprecor, que entre otras consideraciones alcanzó siguiente conclusión en septiembre de $2013^{332}$ :

"Como sabemos los derechos y garantías de los trabajadores subcontratados son claramente inferiores a los de los empleados permanentes, principalmente por los niveles de remuneración y contratación significativamente más modestos, el resultado del proyecto es la profunda y rápida reducción del valor social del trabajo en la vida social y económica de Brasil involucrando potencialmente a millones de personas".

En tercer lugar, la propuesta provocó una reacción inmediata de los Mi-

${ }^{331}$ Información extraída de http://www.industriall-union.org/es/continua-en-brasil-la-luchacontra-la- subcontratacion, consultado 2 julio 2014.

${ }^{332}$ Disponible en el sitio web de Coleprecor: http://coleprecor.wordpress.com/2013/09. 
nistros de la Corte Superior del Trabajo. Diecinueve de los veintiséis miembros de la Corte enviaron un documento al diputado autor del proyecto afirmando que la propuesta provocará un "grave daño social, los derechos sociales, laborales y de seguridad social" en contra de los trabajadores.

Un breve análisis del Proyecto de Ley 4330 permite inferir que en sólo dos párrafos reside el cambio radical de paradigma en las relaciones de trabajo en régimen de subcontratación, una ruptura con la doctrina del trabajo construida por los tribunales durante décadas en aras el establecimiento de límites a la subcontratación y la creación de derechos y garantías para los trabajadores.

El proyecto es breve en su articulado, sólo 19 artículos, y extenso en su justificación. En ella se pone de manifiesto que el origen del mismo se halla en el Proyecto de Ley n ${ }^{\circ} 4302$ de 1998 y en la necesidad de regular un fenómeno expansivo en las últimas décadas, la tercerización; en este sentido, en la justificación del Proyecto se añade que el contenido del mismo supone una garantía para el trabajador y contribuye a la mejora del medio ambiente laboral, para así evitar los fenómenos no deseables que son con frecuencia achacados a la tercerización: la precarización de las relaciones laborales y los altos índices de accidentes de trabajo.

Pasando al contenido sustantivo más polémico del Proyecto en sí -fundamentalmente los artículos relativos al sector privado-, los arts. 1 y 4.2 imponen ya el primer cambio radical: la liberalización de las actividades que pueden ser externalizadas, sin limitación alguna. De tal manera que se podría subcontratar tanto las actividades inherentes de la empresa como las accesorias o complementarias, pero no entrarían dentro del ámbito de aplicación del Proyecto - exclusiones directas, por tanto- la prestación de servicios de naturaleza doméstica y los servicios realizados por las empresas de seguridad (art. 16. II).

Evidentemente esto supone una vuelta de tuerca del sistema brasileño, en el que salvo las excepciones señaladas -seguridad, limpieza, mantenimiento y asistencia técnica- la tercerización a través de contrato de prestación de servicios sólo podría realizarse cuando se tratara de la actividad-medio y no principal de la empresa.

Pero estos artículos suponen también un cambio en el propio concepto de subcontratación que ahora abarcaría cualquier tipo de contrato de prestación de servicios que se realizara entre una persona física o jurídica y una empresa, prestadora de servicios específicos a terceros. En este sentido y, por lo explicado en epígrafes precedentes, el concepto brasileño de subcontratación, en caso de aprobarse el Proyecto, se aproximaría mucho al español, sin entrar en si eso es una buena o mala idea.

Es interesante destacar que el Proyecto reconoce un segundo eslabón en la cadena $-\mathrm{y}$, en este sentido, cabría también un tercero, un cuarto, etc.- de la subcontratación y fija diferentes responsabilidades entre ellos. Así, el art. 2.1 reconoce que la empresa prestadora de servicios puede realizar el trabajo a través de sus propios 
trabajadores - de los que es responsable en virtud de una relación de dependencia y subordinación- o a través de la propia subcontratación de esa actividad encomendada, -no aclara el Proyecto si en todo o en parte- con otra empresa de servicios, incrementando el número de empresas implicadas y, por tanto, en mi opinión, generando mayor complicación de control de las sucesivas cadenas.

Y esto último se agrava por la fijación de diferentes tipos de obligaciones y responsabilidades entre las empresas implicadas, según consta en los arts. 7, 8, 10 y 11, me explico:

Las condiciones de seguridad y salud de los trabajadores son responsabilidad de la empresa contratante, o principal, siempre y cuando los trabajadores estén a su servicio y en sus dependencias o en las que haya designado, liberando de cualquier responsabilidad a la empresa de servicios que es la que realmente ha contratado a los trabajadores (art. 7).

Esta situación difiere significativamente del caso español, en el que en virtud del art. 24 LPRL impera el deber de coordinación de las empresas implicadas en fenómenos interempresariales, pese a que el titular del centro de trabajo donde se desarrolla la actividad al tener una posición preponderante en las relaciones posee también particulares obligaciones respecto de las restantes empresas que operan en el mismo; en este sentido, el párrafo segundo del art. 24 LPRL que las «medidas necesarias» que debe llevar a acabo consisten en informar a las empresas prestadoras de servicio involucradas de los riesgos existentes, propios y generales del lugar de trabajo que puedan afectarles por el desarrollo de sus actividades e informar e instruir sobre las medidas de protección, prevención y emergencia necesarias, en atención a los riesgos. Esta información y formación que reciben las empresas auxiliares deberá trasladarse por ellas mismas a sus propios trabajadores (art. 9.3 RD 171/2004); pero, asimismo, se le impone a la empresa principal o contratante la obligación de comprobar, tanto de manera previa como periódica, la solvencia técnica de la empresa auxiliar, en cuanto al cumplimiento de las normas laborales, de seguridad social y de prevención (rt. 24.3 LPRL en relación con el art. 10.3RD 171/2004).

En segundo lugar, si fuera necesario que el trabajador poseyera una formación específica para la realización del servicio subcontratado, la empresa contratante puede optar por reclamar esa certificación a la empresa de servicios para comprobar la capacidad o formarle ella misma u vez que se haya iniciado ya en su servicio (art. 8). Las interrogantes que surgen respecto a esta disposición son múltiples, ¿no prevalece ninguna de las dos opciones? ¿Qué sucede ante el incumplimiento de la empresa principal de formar al trabajador? ¿No recae sobre la empresa de servicios ningún tipo de coste añadido? Sin respuesta, salvo error u omisión por mi parte, en el Proyecto de Ley.

No existe previsión similar en la normativa española, donde la formación del trabajador es responsabilidad de la empresa contratante -y un derecho del trabajador- y sólo en el caso de la formación específica en materia de riesgos laborales del 
nuevo lugar donde se desempeña el trabajo debe intervenir la empresa contratante o principal (arts. 19 y 24 LPLR).

La empresa principal o contratante tendría una responsabilidad subsidiaria de las obligaciones salariales y de Seguridad social de los trabajadores de la empresa auxiliar relativas al periodo de prestación del servicio, sin perjuicio de la posibilidad de reclamar posteriormente el desembolso, al estilo del solve et repete(art. 10). Y, sin embargo, en caso que la empresa de servicios haya subcontratado la actividad a realizar para el tomador del servicio, con otra empresa-también de servicios- la responsabilidad de la primera empresa de servicios -la que recibe el encargo inicial- con respecto a las mismas obligaciones salariales que debía cumplir la segunda empresa de servicios es solidaria (art. 11). La interpretación conjunta de estos dos preceptos adolece de una incoherencia manifiesta, pues no es posible que la responsabilidad especificada derivada de un mismo fenómeno de descentralización difiera en función de si la empresa es prestadora de servicios o tomadora de los mismos. No se entiende ni se justifica en el Proyecto el porqué de esta divergencia, insisto, sin ningún tipo de coherencia.

Aunque en este aspecto ya nos hemos pronunciado previamente, en España la responsabilidad está configurada, con carácter general, de modo solidario entre las diferentes empresas que intervengan en la cadena de subcontratación, con los límites ya expresados.

Los arts. $4 . \S 1$ y 5 establecen dos interesantes y, en mi opinión, polémicas disposiciones dignas de mención. En primer lugar, se especifica que está prohibida la utilización de los trabajadores por el contratante en actividades distintas de aquellas que fueron objeto del contrato - mercantil, claro está- con la empresa prestadora del servicio. Y, en segundo lugar, se acepta la legalidad del hecho que el trabajador pueda prestar trabajo a través de contratos sucesivos con distintas empresas de servicios para el mismo contratante, de forma consecutiva.

Tal y como están configurados estos dos artículos - con una malísima técnica jurídica-, bajo el prisma de jurista española, se está reconociendo la posibilidad de tráfico ilegal de mano de obra.

La empresa prestadora de servicios, ¿presta un servicio o un trabajador? El Proyecto parece dar la idea de que lo que presta es un trabajador, pues sí se prohíbe la utilización del trabajador por la contratante en otro fin distinto del establecido en el contrato de servicios, se está reconociendo implícitamente que el poder de dirección sobre el trabajador lo ostenta la contratante, encontrándose aquel dentro del ámbito de organización y dirección de ésta.

$\mathrm{Si}$, asimismo, se permite que un trabajador tenga sucesivos vínculos jurídicos, subordinación legal por tanto, de diferentes empresas de servicios pero preste su actividad para la misma contratante consecutivamente y, a su vez, se establezca que no existe vínculo jurídico entre la empresa contratante y el trabajador (según art. $2^{\circ} \S 2$ ), sumándole el hecho de que la contratante le puede aplicar al trabajador 
algunos de los beneficios que sus trabajadores posean (art. $9^{\circ}$ ), se está creando una extraña situación en la que el trabajador es asimilado a los auténticos trabajadores subordinados de la contratante pero se le impide adquirir una condición estable en la empresa donde efectivamente presta servicios -la contratante-, y legalizando, por tanto, su cesión sin un objeto o necesidad temporal real y no permanente.

\section{Conclusiones}

Buena parte de las conclusiones ya han sido vertidas a lo largo del presente texto, pero se pueden resumir como siguen;

El mundo del trabajo afronta grandes y profundas transformaciones, iniciadas en décadas y que nos distancian cada vez más de obtener un empleo estable y permanente. Prevalece la precarización del trabajo, los contratos temporales, la tercerización de los servicios (subcontratación), la degradación de las condiciones de trabajo y la negación de derechos históricamente conquistados.

El importante crecimiento de la tercerización de la mano de obra tiene un efecto positivo para la economía y la competitividad, pero también tiene efectos dañosos para los trabajadores, ya que pierden su vinculación con el verdadero tomador de servicios, reciben salarios menores que los demás trabajadores y peores condiciones de seguridad laboral.

Brasil y España atraviesan diferentes fases económicas, jurídicas y sociales. Brasil se encuentra en una importante fase de estabilidad económica y democrática, con un aumento de su PIB, la elevación de la esperanza media de vida de sus habitantes e, incluso, con el reconocimiento internacional de ser una potencia emergente y, aunque, es cierto que la Constitución Federal, promulgada el 5 de octubre de 1988, trajo avances significativos para los trabajadores, positivando varios derechos, y además extendiéndolos a categorías de trabajadores antes no incluidas, como los trabajadores rurales o los trabajadores domésticos, es necesario mayor protección en este ámbito. España, por el contrario, se encuentra en una fase de recuperación económica y de empleo, pero afrontó los problemas de la subcontratación hace casi décadas con una profusa legislación y con un concepto básico: la extensión de la responsabilidad de manera solidaria a todas las empresas implicadas en un fenómeno interempresarial como la subcontratación.

Aunque en Brasil está planteado un proyecto de Ley de regulación de la subcontratación, los términos del mismo no aparece adecuados para combatir la precarización laboral y el tráfico ilegal de mano de obra, pareciendo que el modelo español adaptado a las circunstancias brasileñas quizá pudiera ser una buena opción. 


\section{Bibliografía}

CRUZ VILLALÓN, J. Outsourcing. Contratas y subcontratas. En: ponencia temática del X Congreso de Derecho del Trabajo y la Seguridad Social. Zaragoza, 1999.

DELGADO, Mauricio Godinho. Curso de Derecho del Trabajo. Sao Paulo: LTr, 2002.

GARCIA NINET J.I. Obligaciones y responsabilidades en materia de seguridad y salud en los supuestos de contratas y subcontratas. Consideraciones en torno al art. 24 (coordinación de actividades empresariales) de la LPRL. En: AAVV, Descentralización productiva y protección del trabajo en contratas. Valencia, 2000.

MARTINS Sergio Pinto. La subcontratación y la legislación laboral. 3 a ed. Sao Paulo:Malheiros, 1997.

MARTINS, Sergio Pinto. La Ley de Subcontratación y Trabajo. $9^{\text {a }}$ ed. rev. yampl. Sao Paulo: Atlas, 2009.

MIÑARRO YANINI, M. La prevención de riesgos laborales en la contratación temporal, empresas de trabajo temporal, y contratas y subcontratas. Ministerio de Trabajo y Asuntos Sociales. Edita Instituto Nacional de Seguridad e Higiene en el Trabajo. Madrid, 2002.

MOLTÓ GARCÍA, J.I. La prevención de riesgos laborales de los trabajadores de las empresas de trabajo temporal en las empresas usuarias. Ministerio de Trabajo y Asuntos Sociales. Edita Instituto Nacional de Seguridad e Higiene en el Trabajo. Madrid, 2009.

MORAES, Paulo Almeida de Douglas. Contratación indirecta y servicios de outsourcing en la actividad principal de las personas jurídicas: la capacidad jurídica y la conveniencia social. 2003. Disponible en: <www.mte.gov.br / policía / ms / ms_monografia.pdf $>$. Consultado el 16 de julio de 2014.

VARGAS, Luiz Alberto de; SILVEIRA, AlmirGoulart da.Terceirização e o enunciado 331 DO TST. Breves considerações. Disponible en:http://lavargas.sites.uol. com.br/terceira.html. 